\title{
Effects of the marihuana homologue, pyrahexyl, on food and water intake and curiosity in the rat'
}

\section{E. L. ABEL and B. B. SCHIFF, University of Toronto, Ontario, Canada}

The drug was administered daily for 6 consecutive days and compared with placebo controls. There was no change in water consumption. There was a depression in food intake and an increase in the time spent exploring other "stimulus" animals. Both effects became more marked on the latter days of testing suggesting possible sensitization to the drug.

The active components in marihuana (cannabis sativa) are its isomeric tetrahydrocannabinols and to date about 80 derivatives of this substance have been synthesized (McGlothlin, 1965). One of these synthetic components is pyrahexyl (synhexyl) (1-hydroxy-3-n-hexyl-6, 6, 9-trimethy 1-7, 8 , 9, 10-t e trahydro-6-diberzoprans). Although pyrahexyl was isolated as early as 1941 (Adams, Loewe, Jelinck, \& Wolff, 1941) there have been few descriptions of the behavioral effects of this substance. The experiments described in this report contain our initial observations of the effects of pyrahexyl on food and water consumption and curiousity in rats.

\section{METHOD}

Twenty albino rats were divided in to two groups which were roughly equivalent with respect to food and water intake and body weight. Fifteen milligrams per kilogram body weight of pyrahexyl dissolved in 5\% alcohol were injected daily into one group of animals for 6 consecutive days while the other group received placebo injections. Curiosity was measured in a $3-\mathrm{ft}$ square box. On one wall there were two small apertures ( $1.5 \mathrm{in}$. square) separated by $1.5 \mathrm{ft}$ through which the experimental animal could observe either a hamster or another rat. The number of "pokes" through the openings and total duration of the "pokes" were recorded automatically by electric counters and clocks whenever the $S$ crossed the beam of a photocell. Animals were tested on 5 consecutive days. Testing began $20 \mathrm{~min}$ after injection and continued for $15 \mathrm{~min}$.

Subjects were on ad lib diets of Purina lab chow and water. Food and water intake, along with changes in body weight, were measured at time of injection every second day for 6 days.

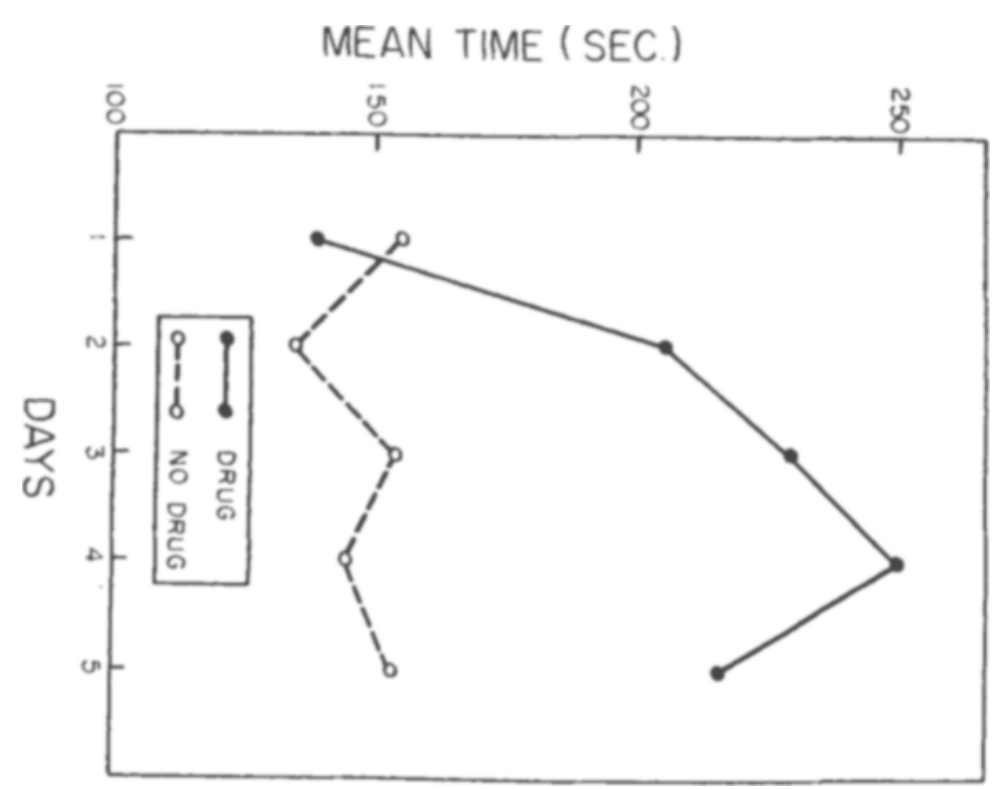

Fig. 1. Mean time spent observing "stimulus" animals on 5 consecutive days of testing.

\section{RESULTS AND DISCUSSION}

There was no main effect of the drug per se on food intake, but there was a significant Drug by Trials interaction $(\mathrm{F}=3.6$, $\mathbf{p}<.05)$. There was also no main effect of the drug on body weight, but again the Drug by Trials interaction was significant $(\mathrm{F}=8.1, \mathrm{p}<.01)$. The control animals showed gradual increases in food consumption and body weight, while the drugged animals showed decreased food intake with successive injections and concomitant depression in body weight. Water consumption was not affected by the drug.

There was no difference between groups in the number of times Ss poked their heads through the openings to observe the other "stimulus" animals. But pyrahexyl-injected animals spent significantly more time in the openings than did control animals $(F=11.1$, $\mathrm{p}<.01$ ). There was also a significant Drug by Trials interaction $(F=2.7, p<.05)$. Figure 1 illustrates the nature of this interaction. The drugged animals showed progressive increases in looking on successive days of testing. There were no differences between the groups on withinsession habituation.
In summary, pyrahexyl led to a decrease in food intake and an increase in curiosity. On both these measures there was a Drug by Trials interaction suggesting potentiation connected with successive administrations of the drug. This may have been due either to a retention of some portion of the drug which summated with further injections, or sensitization. These alternatives are presently being explored.

\section{REFERENCES}

ADAMS, T., LOEWE, S., JELINEK, C., \& WOLFF, $H$. Te trahydorcannabinol homologues with marihuana activity. Journal of the American Chemical Society, 1941, 63, 1971-1976.

CHOPRA, R. N., \& CHOPRA, G. S. The present position of hemp-drug addiction in India. Indian Journal of Medical Research, 1939, Supplement No. 31.

McGLOTHLIN, W. H.Cannabis: A reference. In P. Solomon (Ed.), The marihuana papers. New York: Signet Press, 1968.

\section{NOTE}

1. The authors would like to express their thanks to Dr. P. Cooper (Department of Pharmacology, University of Toronto) for making this study possible.

2. This research was supported by Grant No. NRC APB 149. 